\title{
Foucault e Heidegger A ética e as formas históricas do habitar (e do não habitar)
}

\author{
LUÍS CLAUDIO FIGUEIREDO
}

\begin{abstract}
RESUMO: A partir de uma entrevista em que Foucault coloca a obra de Heidegger como uma das duas bases fundamentais de seu próprio pensamento (a outra é Nietzsche), o texto desenvolve uma das possibilidades de aproximação entre Heidegger e Foucault: a compreensão da ética enquanto morada e habitação. Os trabalhos derradeiros de Foucault, em que se renova o pensamento da ética através de um nítida separação entre ética e moral e mediante uma análise da ética enquanto procedimentos e técnicas de subjetivação - as tecnologias de si - são então contemplados por este ângulo. Ao final, é retomada e discutida a última mensagem de Foucault, a sua proposta de uma ética entendida como uma nova estética existencial.
\end{abstract}

\section{Foucault e Heidegger?}

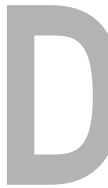

ada uma relação que é sem dúvida muito significativa, que passa por natural e de todos conhecida entre Foucault e Nietzsche, cabe, de início, perguntar acerca do sentido e da pertinência da aproximação que aqui se fará entre Foucault e Heidegger. Para os leitores de um dos mais belos e elucidativos textos sobre o conjunto da obra de Michel Foucault - Michel Foucault: Beyond structuralism and hermeneutics, de Dreyfus e Rabinow - esta aproximação não surpreende. Assinalo, inclusive, que há uma entrevista de Foucault autorizando explicitamente esta relação. Diz ele: "Fiquei surpreso quando dois amigos de Berkeley escreveram que eu fora influenciado por Heidegger. Certamente é verdade, mas ninguém na França o tinha enfatizado" (Foucault, 1994, p.780). Contudo, é numa outra entrevista, concedida no dia 29 de maio de 1984, menos de um mês antes de sua morte, ocorrida em 25 de junho, que Foucault diz o que era necessário

\section{UNITERMOS:}

Foucault, Heidegger, ética, modos de subjetivação, estética existencial.
Professor do Departamento de Psicologia Experimental do IP. USP, da PUC-SP e da UNIP 
dizer sobre sua vinculação a Heidegger:

"Certamente Heidegger foi para mim o filósofo essencial(...). Todo meu futuro filosófico foi determinado por minha leitura de Heidegger (...). Meu conhecimento de Nietzsche é bem melhor do que o que tenho de Heidegger; não obstante foram estas as minhas duas experiências fundamentais. É provável que se não tivesse lido Heidegger não teria lido Nietzsche. Tinha tentado ler Nietzsche nos anos cinqüenta, mas Nietzsche sozinho não me dizia nada. Enquanto que Nietzsche e Heidegger, aí sim, este era o choque filosófico. Mas nunca escrevi nada sobre Heidegger e nada escrevi sobre Nietzsche além de um pequeno artigo. São, contudo, os autores que mais li. Creio que é importante termos um pequeno número de autores com os quais se pensa, com os quais se trabalha, mas sobre os quais não se escreve" (Foucault, 1994, p. 703).

O que, brevemente, pode ser identificado como o legado heideggeriano na obra de Foucault? Certamente é um legado multifacético, mas, sem dúvida todas estas faces nos remetem à crítica empreendida por Martin Heidegger às metafísicas do sujeito, ou seja, à crença num sujeito como fundamento auto-fundante do mundo e das representações. Quando Foucault afirma:

"Penso que não há sujeito soberano, fundador, uma forma universal de sujeito que poderíamos encontrar em toda parte" (Foucault, 1994, p.733).

tema que atravessa toda a sua produção, estamos indiscutivelmente no campo reflexivo instaurado por Heidegger com sua "destruição da metafísica" e, em particular, com sua crítica à metafísica da Modernidade. Embora o método genealógico seja uma criação de Nietzsche, não tenho dúvidas de que somente a destruição da metafísica do sujeito heideggeriana abriu o espaço para a obra de genealogista realizada por Foucault.

\section{0 interesse em Foucault}

As genealogias elaboradas por Michel Foucault exploraram três domínios:

"De início uma ontologia histórica de nós mesmos em nossas relações com a verdade, que nos permitem que nos constituamos como sujeitos do conhecimento; em seguida, uma ontologia histórica de nós mesmos em nossas relações com um campo de poder onde nos constituímos como sujeitos capazes de agir sobre outros; enfim, uma ontologia histórica de nos- 
sas relações com a moral, que nos permitem nos constituirmos como agentes éticos. Todos os três eixos estavam presentes, mesmo que de uma maneira um pouco confusa na História da loucura. Estudei o eixo da verdade no Nascimento da clínica e na Arqueologia do saber. Desenvolvi o eixo do poder em Vigiare punir e o eixo moral na História da sexualidade" (Foucault, p. 393).

A mim, particularmente, a partir de meus interesses psi, são os dois últimos eixos mencionados - os das "técnicas de dominação", com seus estudos das disciplinas, dos governos, das bio-tecnologias, e o das "técnicas de si” - os que mais atraem a atenção. Vale mencionar que ambos os eixos tendiam na obra de Foucault a uma certa integração, como se depreende de um dos seus últimos textos - sua participação em 1982 na Conferência sobre A Tecnologia Política dos Indivíduos. Neste trabalho, entre outras indicações dos rumos futuros de suas pesquisas - que retornaria à questão das bio-tecnologias, após os estudos sobre as técnicas de si que resultaram nos dois últimos volumes da História da sexualidade, além de inúmeros textos avulsos que seriam material para o quarto volume (As confissões da carne) - Foucault afirma que

\section{"A característica maior da racionalidade moderna não é nem a constituição do Estado, nem a emergên- cia do individualismo burguês, mas o seguinte fato: a integração dos indivíduos a uma comunidade ou tota- lidade resulta de uma correlação permanente entre uma individualização sempre mais avançada e a con- solidação desta totalidade” (Foucault,1994, p. 827).}

Assim sendo, as técnicas de dominação (governo) e as técnicas de $s i$, as principais responsáveis pelo adensamento das subjetividades individuais, articulam-se na constituição da subjetividade moderna e contemporânea (e daí o interesse crescente de Foucault nas questões do liberalismo). Esta articulação, por sinal, foi o objeto da análise da contemporaneidade que tentei elaborar nos últimos capítulos de meu livro A invenção do psicológico. Quatro séculos de subjetivação (1500-1900), ao mostrar as íntimas e paradoxais alianças que se formam entre liberalismos e disciplinas desde o século XIX, tema a que retornarei adiante.

\section{3. $O$ âmbito das éticas}

Uma das principais contribuições de Foucault para o estudo genealógico das subjetividades reside, creio eu, na sua concepção do que é abrangido pelo campo da ética. Ao separar conceitualmente dois domínios - o dos códigos morais e o dos atos ou condutas - enfatizando este segundo como decisivo para a constituição das subjetividades, ele abriu um vasto campo de pesquisas e descobertas. 
Nesta seção, o material que estou apresentando se baseia em grande parte no meu artigo Etica, saúde e práticas alternativas (1995) em que as relações da ética com o habitar e deste com a saúde são mais desenvolvidas.

2 Para as considerações que se seguem vali-me dos textos de Heidegger Batir habiter penser (1986), Sérénité (1990) e Pour Servir de Commentaire a Sérénité. Foi-me também de grande valia a fenomenologia do habitar desenvolvida por E. Lévinas em Totalité et Infini (1990), embora no conjunto as elaborações levini-anas sobre a ética pretendam se colocar em oposição a Heidegger.
A dimensão ética da existência abarca, naturalmente, o campo de nossas relações com os outros mediadas, explícita ou implicitamente, por códigos de prescrições e proibições, por padrões de legitimação das condutas. Porém, a dimensão ética implica fundamentalmente os humanos em relações reflexivas, vale dizer, instauram-se aqui relações de cada um consigo mesmo. É no âmbito destas relações de si para consigo que as propostas analíticas de Foucault parecem mais fecundas. Numa rápida recapitulação, estas relações podem, segundo ele, ser analisadas em quatro aspectos: (1) o da substância ética (isto é, a parte de si que é visada pelo ditames morais), (2) o modo de assujeitamento (ou seja, o modo dos indivíduos reconhecerem a força destes ditames), (3) os meios acionados para os controles e transformações desejadas (vale dizer, os procedimentos ascéticos e ensinantes da ética) e, finalmente, (4) a teleologia de todo este processo (que são os ideais normalizadores e norteadores de todos os esforços de transformação, definindo o tipo de homem perseguido nos processos de subjetivação). Estes quatro aspectos não são meros reflexos passivos das experiências humanas: eles têm, articulados aos códigos, uma eficácia constitutiva. Por outro lado, como sabemos, para Foucault tanto os códigos de prescrições e proibições como, e principalmente, as relações consigo são históricas e sujeitas a amplas variações e múltiplas combinações. Assim, as pesquisas genealógicas visam responder a seguinte questão:

\section{"Como nós constituímos nossa identidade por meio de certas técnicas éticas de si que se desenvolveram desde a antiguidade até nossos dias?" (Foucault, 1994, p. 814)}

\section{A ética e o habitar ${ }^{1}$}

A questão que me ocorre é a seguinte: haverá, para além destas variações e sem se opor a elas uma figura que metaforize a dimensão ética da existência em toda a sua complexidade e eficácia? Recorrendo aqui explicitamente a Heidegger proponho a casa, a morada, o habitar ${ }^{2}$. Já no plano etimológico, ethos se refere tanto aos costumes como a morada. Na verdade, hábitos e habitações compartilham a mesma raiz.

O homem é arremessado num mundo que ele não escolheu e é aí como a abertura ao que deste mundo lhe vem ao encontro, ou seja, ele existe no sentido preciso de ser fora de si mesmo, de ser o seu fora. Ora sustentarse neste existir, e só assim se existe, exige um espaço de separação, de recolhimento, de proteção que não encerre o existente numa clausura, mas lhe ofereça uma abertura limitada em que se reduzam os riscos dos maus encontros.

É claro que uma casa, qualquer feitio que ela tome pode ser concebida como um aparelho para morar ou como um monumento a ser apreciado de fora. No entanto, para quem a habita e enquanto a habita, a casa não é utensílio e objeto, tal como os demais entes. A casa tem, como o próprio mundo, uma natureza pré-objetal, ela é como uma parte do mundo, mas exatamen- 
te aquela parte em que podemos nos sentir relativamente abrigados. Pois bem, considerar o ethos como uma casa, como uma instalação, é ver nele, nos códigos, valores, ideais, posturas, condutas para consigo mesmo e para com os outros algo equivalente à moradia.

O habitar sereno e confiado é a condição do gozar, do fruir, ou seja da experiência do corpo como fonte de prazer - mesmo que limitado - livre dos riscos e das incertezas.

Mas o habitar sereno e confiado deve ser visto também como condição do trabalhar, ou seja, do apropriar-se pelo trabalho dos elementos naturais do mundo para convertê-los também em proteção, alimento e gozo.

Finalmente, é no relativo distanciamento dos acontecimentos do mundo "lá fora", propiciado pela habitação, que podemos desenvolver nossas capacidades cognitivas, tanto na via do conhecimento representacional, calculador e científico, como na do jogo e da criação, como na da meditação filosófica. O habitar sereno e confiado é assim também a condição do pensar, do representar, do brincar e do experimentar, exatamente porque o abrigo da casa nos dispensa uma acolhida que nos dispensa de maiores esforços.

Poderíamos também chegar a resultados semelhantes tomando como ponto de partida a psicanálise, principalmente a psicanálise desenvolvida pelo grupo independente da escola inglesa (Winnicott, Balint, Bollas, etc.) e pela psicologia do self (Kohut) cujas afinidades com a filosofia de Heidegger já foram assinaladas por diversos autores ${ }^{3}$. Estudos psicanalíticos daí provenientes nos revelam como o desenvolvimento psíquico de cada um de nós exige que, nos inícios da vida, a criança seja acolhida e tenha a oportunidade de uma inserção pré-objetalizada e pré-representativa no mundo. A mãe como "ambiente facilitador" (Winnicott), os pais como "self-objetos" (Kohut) ou como "objetos transformacionais" (Bollas) remetem-nos a esta condição em que os outros ainda não estão plenamente diferenciados em sua alteridade, mas, ao contrário, cuidam da criança como se fossem uma parte dela mesma. As obras destes autores revelam também que experiências deste tipo continuam ocorrendo durante todo o processo normal de desenvolvimento e ao longo de toda a vida. Há sempre ocasiões em que partes do ambiente social e físico nos oferecem - gratuitamente - um certo resgate dessa relação primária com o entorno. Em contrapartida, a ausência precoce destas experiências, que dão ao indivíduo a "quietude do centro" (Margaret Little), deixa marcas profundas no processo de desenvolvimento, embora, naturalmente, seja o destino de todos nós o enfrentamento de situações de maior diferenciação, isolamento, responsabilidade e risco. Contudo, é somente a partir de um primordial sentir-se em casa que se criam as condições para as experiências de encontro de alteridades e para os conseqüentes acontecimentos desalojadores.

Entre as partes do ambiente que, num processo normal, continuarão sempre a exercer, num nível pré-reflexivo, estas funções protetivas, sustentadoras, acolhedoras, que nos oferecem renovadamente a "quietude do centro”, ressaltamos as moradas, sejam as casas materiais de madeira, pedra,
${ }^{3}$ Elsa Oliveira Dias e Zeljko Loparic', entre outros, já publicaram alguns trabalhos explorando estas ressonâncias. 
tijolos ou mesmo papelão, sejam as moradas simbólicas proporcionadas pelo ethos. Uma ética, na verdade, institui uma troca regulada de afetos e obrigações recíprocas entre os indivíduos. É esta reciprocidade que permite que cada um possa, dentro de certos limites, confiar, contar com a presença de alguns outros - em maior ou menor número - como self-objetos em algumas circunstâncias. Mais que isso, a reflexividade implicada nas éticas, ou seja, as relações de si para consigo, fazem com que partes de um indivíduo possam assumir com alguma autonomia e diante dele mesmo certas funções antes exercidas pelos outros. Poderíamos dizer, então, que o sujeito ético pode desenvolver a capacidade de manter e, numa certa medida, edificar sua própria morada com uma relativa independência.

\section{As formas históricas do habitar o mundo}

Gostaria agora de tratar com a brevidade que a circunstância requer das formas históricas do habitar o mundo.

Numa rapidíssima recapitulação poderíamos nos reportar, de início, ao que chamei de ética coesiva. O testemunho de antropólogos e historiadores nos ensina um pouco acerca do ethos das chamadas civilizações fechadas. Observa-se aí um enraizamento quase fusional da comunidade na natureza - ambas miticamente interpretadas - e de cada 'indivíduo' na sua comunidade. O cosmos e a ordem social confundem-se e em ambos as posições de cada um estão perfeitamente definidas, deixando um reduzido espaço para a individualização singularizada. Corpo, vestes, casa e mundo; narrativas, rituais e atividades cotidianas estão perfeitamente entrelaçados e integrados a um sistema de compreensão e ação. No centro dessa ordem estão os espaços, tempos, personagens, gestos e falas sagrados em que a realidade se mostra verdadeiramente e em torno dos quais se estende a trama do sentido. $\mathrm{O}$ ethos coesivo domina, englobando sob o mesmo teto os seres humanos, os animais, as plantas e forças da natureza. Trata-se de uma morada ampla e sólida, resistente e exclusiva. Fora dela é o pavor do nada, fora dela, os inimigos.

Vai ser da perda de vigência desta casa sólida, resistente e comunitária que nascerão os esforços mais ou menos explícitos de reconstrução das moradas; trata-se do campo em que se configura o que os modernos chamarão de Razão Prática, campo que permite e exige uma reflexão acerca dos modos desejáveis e legítimos de conduta. Surgem então questões do tipo: como se conduzir adequadamente com os outros e consigo mesmo?; como e sobre que condutas exercer um autodomínio?; como moderar-se, como conter sua natureza?; como educar-se e trabalhar na construção de sua subjetividade?; como cuidar de si?

Este pode ser o momento de acrescentar algumas palavras do próprio Foucault que me parecem corroborar, incidentalmente, a aproximação dos seus estudos sobre as técnicas éticas de si à problemática heideggeriana do habitar. Diz ele:

\section{“Ocupar-se de si - o que de uma forma ou de outra está}


presente em toda ética desde a falência da ética coesiva - não é uma preparação para a vida; é uma forma de vida. (...) Não há outro fim nem outro termo além do propósito de estabelecer-se junto a si, 'residir em si mesmo', fazer aí sua morada” (Foucault, 1994, p. 356).

Em muitas sociedades e épocas, perguntas a respeito de que casa construir e de como fazê-lo podiam ser respondidas tomando-se como pressupostas as posições dos indivíduos na trama social em que existiam com seus estatutos e papéis institucionalizados. Gerava-se, assim, o que podemos designar como uma ética da excelência (MacIntyre, 1988; Ferry, 1995) ou uma estética existencial (Foucault): cada um era chamado a realizar por conta própria o trabalho de se impor um estilo de vida que se orientava pela idéia de perfeição, auto-superação, excelência no exercício de sua função e na ocupação do seu lugar.

Em níveis mais avançados de individualização, começam a faltar os pressupostos para uma ética da excelência exclusiva e dominante, embora uma certa noção de excelência esteja presente até os tempos modernos orientando à distância os movimentos de subjetivação. Vai ocorrer porém uma fragilização das identidades posicionais e, em decorrência, dá-se uma problematização muito mais severa das condutas individuais. O resultado foi o surgimento e aperfeiçoamento do que Foucault denominou de cultura das práticas de si, dos cuidados, às vezes obsessivos, de cada um consigo mesmo. Exames regulares e sistemáticos da própria consciência, práticas de registros de vida e de escrita de si, trocas de cartas pessoais, confissões, etc., foram alguns dos procedimentos desenvolvidos e acionados para a sujeição dos indivíduos a seus próprios cuidados: é como se a partir daqui cada um se convertesse plenamente no edificador de sua própria morada, de uma morada talvez ainda bastante padronizada, mas já feita sob medida para cada um. Acentua-se desde então a dimensão ascética da conduta ética, ao mesmo tempo em que se reduz a sua dimensão estética. O problema já não é o de imporse um estilo, mas o de renunciar em nome de alguma noção de pureza ou da expectativa de um ganho futuro.

Embora estes procedimentos de cuidados de si tenham desde a antigüidade romana e, muito particularmente, desde o advento da cultura cristã se convertido numa verdadeira cultura e, assim, contribuído decisivamente para a constituição das subjetividades modernas, foi apenas quando o cuidado de si veio a carecer quase que completamente de uma base coletiva, consensual e tradicional na definição das metas e das formas legítimas da ação que estas práticas conquistaram seu pleno florescimento. Em outras palavras, são as situações de desenraizamento profundo tanto das sociedades em relação às suas condições naturais, como dos indivíduos em relação às suas comunidades que engendram as mais intensas exigências de cuidar de si e de construir/ reconstruir nossas moradas. Ao mesmo tempo, naturalmente, são estas as situações em que mais desnorteados estamos para empreender esta construção. 
A tendência dominante nestes tempos será, então, a de se colocar a eficácia das soluções éticas no lugar que antes fora ocupado pela excelência: trata-se agora de escolher ou justificar escolhas em termos de seus efeitos, das suas conseqüências para a vida, para o sucesso, para felicidade de cada um ou do conjunto.

É neste contexto, o contexto do individualismo moderno, que a ética liberal articula um projeto de mundo e promove procedimentos de autodomínio organizados pelas noções de soberania do indivíduo e de mérito individual. Mas é também neste contexto que, diante dos impasses e precariedades dos liberalismos, emergem e se consolidam as práticas disciplinares, tão focalizadas por Foucault em suas pesquisas sobre as bio-tecnologias. Estas disciplinas, todavia, além de fazerem parte do campo das técnicas de dominação e governo, geram suas próprias técnicas éticas de si organizadas pelas noções de integração, ajustamento e funcionalidade. Por outro lado, é do trituramento de certos valores e posturas liberais pelas práticas disciplinares nos contextos da vida pública e doméstica que emergem os mais intensos apelos da ética romântica, organizada pelas noções de pertinência, participação e autenticidade.

Minha sugestão, desenvolvida detalhadamente em outro trabalho (Figueiredo, 1992) é a de que jamais se pensem liberalismos, disciplinas e romantismos em suas puras diferenças e aparentes antagonismos. A "presença" de cada um dos pólos de nossa cultura contemporânea deveria ser concebida a partir, talvez, da noção de diferança proposta por Derrida:

"A diferança é o que faz com que o movimento de significação não seja possível a não ser que cada elemento dito 'presente', que aparece sobre a cena da presença, se relacione com outra coisa que não ele mesmo, guardando em si a marca do elemento passado e deixando-se moldar pela marca de sua relação com o elemento futuro(...) é necessário que um intervalo o separe do que não é ele mesmo para que ele seja ele mesmo, mas este intervalo que o constitui em presente deve, no mesmo lance, dividir o presente em si mesmo, cindindo-o" (Derrida, 1991, p. 45).

Acredito que os liberalismos, as disciplinas e os romantismos sejam, cada um deles, o diferendo (o diferente e o adiamento) dos outros dois, que cada um deles seja o rastro do passado e o rastro do futuro, rastros dos outros que fazem de cada um o que ele é, mas que, por isso mesmo, fazem de cada um um presente cindido. Só assim, sob o signo da diferança, podem ser pensados os três pólos constitutivos da ética contemporânea e é sob este signo que se constituem nossas subjetividades marcadas pelos rastros dos liberalismos, das disciplinas e dos romantismos. É o caráter inapreensível deste "signo" que torna o contemporâneo um território da ignorância: neste território, cada posição, cada identidade contém em si mais - e menos - do que é 
capaz de reconhecer. É a diferança na sua produtividade invisível que nos faz a todos uma realidade heterogênea de rastros: rastros liberais, rastros disciplinares, rastros românticos. Uma "realidade", portanto, nunca presente a si mesma, já que constituída sempre pelos intervalos que nos separam dos outros e de nós mesmos.

Creio que é desta experiência perturbadora de sermos habitados por três diferantes sem podermos habitar serena e confiadamente uma só casa, é desta experiência de radical desterritorialização que emerge uma figura paradigmática da cultura do narcisismo, como a do "mínimo-eu" estudada por Christopher Lash. O mínimo-eu é o produto do esforço de conservar o idêntico na sua presença mais forte e, supostamente, menos cindida: aqui, agora. A ética de sobrevivente do mínimo-eu, se é que de ética ainda se trata, implica num investimento maciço em si mesmo, sem a disposição para assumir uma história e para fazer promessas. O mínimo-eu é o preço pago pela recusa em ser apenas uma composição dinâmica de rastros heterogêneos. É o esforço desesperado, auto-mutilante, mas infrutífero, de estar presente a si mesmo sem faltas, sem falhas, sem restos e sem sobras.

Penso que é apenas a partir de uma radical experiência de desterritorialização e, inclusive, de uma observação rigorosa da cultura do narcisismo que Foucault pode elaborar sua derradeira mensagem: a proposta de uma renovada estética existencial. Fazer da vida uma obra de arte, sem qualquer compromisso com a autenticidade (crítica a Sartre; Foucault, 1994, p. 392, 617), sem qualquer procura de uma verdade de si (crítica ao cultivo de si californiano; Foucault, 1994, p. 402, 624): a pura e simples afirmação de uma arte de viver, tal como ele sugere ao movimento gay, em contraposição a qualquer ciência ou conhecimento científico da sexualidade (Foucault, 1994, p. 735).

Ora, como entendermos esta idéia? Decididamente, fazer da vida uma obra de arte não guarda nenhum parentesco com os esteticismos, seja o dos antigos dandys dos fins do século passado, seja o dos novos yuppies do nosso fim de século. Não se trata para Foucault, obviamente, de maquiar, decorar e perfumar a vida. Uma outra interpretação possível seria a de supormos em Foucault uma nostalgia grega, ou seja, um desejo de reeditar a estética existencial dos antigos, o que daria ao pensamento derradeiro de um "pósmoderno" como Foucault um caráter paradoxalmente anacrônico. Julgo, porém que a partir da estética de Nietzsche e de sua noção de grande estilo podemos fazer uma leitura muito mais instigante da proposta foucaultiana. Em um Fragmento Nietzsche afirma:

"A grandeza de um artista não se mede pelos" belos sentimentos "que ele suscita, mas pelo grau de aproximação ao grande estilo, pelo grau em que se é capaz do grande estilo. Este estilo tem em comum com a grande paixão o fato de desdenhar o prazer, de se esquecer de persuadir, de mandar, de querer... Dominar o caos que se é, obrigar o próprio caos a tornar- 


\section{se forma"(Nietzsche, 14(61) de 1988).}

O grande estilo é o que resulta da capacidade de nos tornarmos senhores do caos que somos em nós mesmos, sem mutilar as forças em combate, forçando o caos a tomar forma (Ferry, 1995). Fazer da vida uma obra de arte seria assim suportar todas as tensões instituídas pela diferança, pelos intervalos, pelos vestígios, pelas antecipações, pelos diferendos de que somos feitos. Nesta perspectiva, fazer da vida uma obra de arte seria o mais radical contraponto ao mínimo-eu que se constitui e conserva mediante as mais severas mutilações.

Se há alguma viabilidade nesta proposta, não se sabe e talvez apenas o futuro nos diga. Aparentemente, contudo, a carga de tensão que ela exige suportar e o potencial trágico que ela contém jamais permitiriam que uma estética existencial concebida a partir da noção de grande estilo pudesse ser amplamente acolhida e experimentada. Na verdade, por enquanto o que vemos é que as experiências de desenraizamento radical, capazes de gerar, por um lado, a cultura narcisista do mínimo-eu, vem gerando, de outro lado, formas extremamente mortíferas, e igualmente narcisistas, de reterritorialização. A falta de uma casa, a falta de um ethos confortável e sustentador está, creio eu, na raiz das ondas nacionalistas, racistas e xenófobas dos últimos anos; está na raiz de um cultivo belicoso e intolerante dos particularismos e das pequenas diferenças, está na raiz dos muitos processos agressivos de retribalização.

Infelizmente, já não podemos contar com Foucault para nos acompanhar nesta difícil travessia.

Recebido para publicação em abril/1995

UNITERIMS:

Foucault, Heidegger, ethics, modes of subjectivation, esthetic of existence.
ABSTRACT: Based on an interview given by Foucault where he acknowledges the work of Heidegger and Nietzsche as the two main pillars of his own thought, the essay explores one way of approximating Heidegger and Foucault: the understanding of ethics as dwelling and inhabitation. The renewal of thought on ethics which takes place in the latest works by Foucault, through a sharp separation between ethics and moral philosophy and through an analysis of ethics as procedures and techniques of subjectivation - as technologies of self - are being here analysed from the point of view of ethics as dwelling and inhabitation. Finally, Foucault's last message, his proposition of ethics understood as an new esthetic of existence is here recuperated and discussed.

FIGUEIREDO, Luís Claudio. Foucault e Heidegger. The ethics and the historical forms of the inhabiting (and of the not inhabiting). Tempo Social; Rev. Sociol. USP, S. Paulo, 7(1-2): 139-149, october 1995. 


\section{REFERÊNCIASBIBLIOGRÁFICAS}

DERrIDA, J. (1991) A diferença. In: . Margens da filosofia. São Paulo, Papirus.

Dreyfus H. \& Rabinow P. (1982) Michel Foucault: Beyond structuralism and hermeneutics. Brighton, The Harvester Press.

FERry, L. (1995) Homo Aestheticus. São Paulo, Ed. Ensaio.

FigueIredo, Luís Claudio .(1992) A Invenção do Psicológico. Quatro séculos de subjetivação (1500-1900). São Paulo, Ed. Escuta/Educ.

FigueIREdo, Luís Claudio. (1995) Ética, saúde e práticas alternativas. In: . Revisitando as Psicologias. Da epistemologia à ética das práticas e discursos psicológicos. Petrópolis, Vozes/Educ.

Foucault, Michel. (1994) Dits et écrits -1954-1988. Vol. IV, 1980-1988. Paris, Gallimard.

MacInTyre, A. (1988) Whose justice? Wich nationality? Scoth Meredith, New York.

HeIdegger, Martin. (1986) Batir habiter penser, In: . Essais et Conférences. Paris, Gallimard. . (1990) Pour servir de commentaire a Sérénité. Questions III et IV. Paris,Gallimard. . (1990) Sérénité. In: . Questions III et IV. Paris, Galimmard.

LÉvinas, E. (1990) Totalité et infini. Paris, Kluwer Academic. 
FIGUEIREDO, Luís Claudio. Foucault e Heidegger. A ética e as formas históricas do habitar (e do não habitar). Tempo Social; Rev. Sociol. USP, S. Paulo, 7(1-2): 139-149, outubro de 1995. 